\title{
СОВРЕМЕННОЕ ОБРАЗОВАНИЕ И ДАЛЬНЕЙШЕЕ РАЗВИТИЕ ИНФОРМАЦИОННОГО ОБЩЕСТВА
}

\author{
О. Э. Башина, В. Н. Николенко \\ (Московский гуманитарный университет)
}

\begin{abstract}
Аннотация: В статье анализируются основные черты информационного общества, обеспечивающие новые возможности в образовании. Рассмотрены особенности современного онлайн образования. Подтверждается тезис о вероятном дальнейшем расслоении общества на малочисленную «научно-информационную элиту» и массового потребителя.
\end{abstract}

Ключевые слова: информационное общество; онлайн образование; информационные технологии; расслоение общества

\section{CONTEMPORARY EDUCATION AND FURTHER DEVELOPMENT OF THE INFORMATION SOCIETY}

\author{
O. E. Bashina, V. N. Nikolenko \\ (Moscow University for the Humanities)
}

\begin{abstract}
The article analyzes the main features of the information society which provide new opportunities in education. Also discussed is the structure of contemporary online education. We argue that the trends described in the article may potentially bring about further stratification of society into small scientific and informational elites and the mass consumer.

Keywords: Information society; online education; information technology; stratification of society
\end{abstract}

Наука и образование в информационном обществе приобретают новые черты, качества и особенности. Это диктуется, прежде всего, тем, что именно обмен информацией и новые качества ее доступности предоставляют новые возможности для развития этих сфер общественной жизни и существования индивидуумов, составляющих такое общество. При этом большинством исследователей принимается - явно или неявно - положение об устойчивом развитии общества.

Концептуальные основы устойчивого развития как учения о ноосфе- 
ре были заложены В. И. Вернадским. Под ноосферой он понимал, как отмечают исследователи его взглядов, такую стадию «эволюции биосферы Земли, на которой в результате победы коллективного человеческого разума начнут согласованно развиваться и сам человек как личность, и объединенное человеческое общество, и целесообразно преобразованная людьми окружающая природная среда» (Яншина, 1996: 210).

В настоящее время на фундаменте представлений об устойчивом развитии происходит становление интегральной ноосферной общенаучной парадигмы знаний, которая возникает как результат широкого синтеза наук о природе, обществе и человеке, т. е. трех основных направлений развития бытия. Эта бурно развивающаяся сфера знаний обладает развитым внутренним синергетическим свойством организовывать вокруг себя новые направления научной систематизации информации и результатов исследований (Левашов, 2013).

Технологической основой такого развития на настоящем этапе является современный уровень возможностей компьютерного и телекоммуникационного оснащения, которые в целом позволяют декларировать начало становления информационного общества.

Приведем одно из возможных определений информационного общества: информационное общество - общество, в котором большинство работающих занято производством, хранением, переработкой и реализацией информации, особенно высшей ее формы - знаний. Деятельность людей сосредоточивается главным образом на обработке информации, а материальное производство и производство энергии возлагается на машины.

Подчеркнем основные декларируемые признаки информационного общества (ИО):

1. Осознание обществом приоритетности информации перед другим продуктом деятельности человека;

2. Первоосновой всех направлений деятельности человека (экономической, производственной, политической, образовательной, научной, творческой, культурной и т. п.) является информация;

3. Информация же является продуктом деятельности современного человека;

4. Информация в чистом виде (сама по себе) является предметом купли-продажи;

5. Равные возможности в доступе к информации всех слоев населения;

6. Безопасность информационного общества, информации;

7. Защита интеллектуальной собственности;

8. Взаимодействие всех структур государства и государств между собой на основе ИКТ;

9. Управление информационным обществом со стороны государства, 
общественных организаций.

Однако, кроме положительных моментов, прогнозируются и опасные тенденции:

- все большее влияние на общество средств массовой информации;

- информационные технологии могут разрушить частную жизнь людей и организаций;

- существует проблема отбора качественной и достоверной информации;

- многим людям будет трудно адаптироваться к среде информационного общества.

- существует опасность разрыва между «информационной элитой» (людьми, занимающимися научными исследованиями и разработкой новых технологий, в том числе информационных) и потребителями.

Для наступающего шестого (кондратьевского) технологического уклада (Кондратьев, Опарин, 1928) уже сейчас просматриваются такие определяющие особенности, как тотальный доступ к информационным сетям и образовательным курсам, индивидуализация образования, онлайн-образование.

Внутри «длинных волн» наблюдаются, как правило, классические деловые экономические циклы, длительностью 7-10 лет, которые соответствуют особенностям рыночной экономики - начиная от внедрения отдельных технологий в производство и до спада потребления соответствующей продукции. Краткосрочные (2-3 года) экономические циклы, заключенные внутри классических, определяются темпами принятия и реализации решений коммерческими фирмами в рамках рыночной экономики (Акаев, Садовничий, 2012).

Роль статистики в шестом технологическом укладе становится принципиально новой (Башина, Минашкин, 2014). Статистика приобретает значение, принципиально отличное от прежнего. Статистика находится как бы «над» всей совокупностью технологий, социально-экономических и иных параметров общества. Статистика в новом технологическом укладе становится главным инструментом предвидения все ускоряющихся изменений в структуре общества, параметрах экономики, совокупности новых технологий. Статистика во многом становится инструментом и методологией получения новых знаний о процессах и явлениях в жизни общества во всех мыслимых разрезах - от индивидуализированных распределений характеристик и предпочтений отдельных лиц и до обобщенных тенденций развития цивилизации в целом.

Новая роль статистики обусловлена еще и тем, что в условиях тотальной компьютеризации и развития информационных сетей краткосрочные экономические циклы (2-3 года) пятого технологического уклада бу- 
дут, с очевидностью, принципиально сокращаться, так как запаздывание информации (об экономической обстановке, о действиях конкурентов и т. п.) будет существенно меньшим. По-видимому, будут сокращаться и среднесрочные (7-10 лет) экономические циклы, поскольку в шестом технологическом укладе просматривается неизбежное сокращение времени на перестройку базовых (массово востребованных потреблением) технологий и производств.

Эти факторы превращают статистику из инструмента фиксации состояний в инструмент и методологию оперативной подготовки информации для принятия решений на всех уровнях управления, от малого бизнеса до государственных и межгосударственных органов. Более того, статистика становится основным инструментарием выявления новых значений и смыслов происходящего.

Таким образом, очевидно, что для реализации новой роли статистики - и как научного направления, и как прикладной дисциплины - coвершенно необходим принципиально новый подход к статистическому образованию. Это относится ко всем уровням статистического образования, используемого во всех областях развития социума и экономики, поскольку статистика становится инструментом, прежде всего, содержательного анализа и предвидения.

Каковы же особенности образования и его развития в условиях строящегося информационного общества?

В сфере образования - это, прежде всего, доступность информации о возможностях и основном содержании образования. Следующий положительный, несомненно, момент - тенденция опубликования многими мировыми центрами образования, т. е. ведущими вузами планеты, курсов по многим и многим дисциплинам, что делает образование значительно более доступным, нежели ранее.

Однако необходимо отметить следующие особенности всей системы онлайн-образования.

Во-первых, публикуются отдельные курсы, соотнесенные, в лучшем случае, с направлениями подготовки будущих специалистов (в дальнейшем обобщенного обучаемого будем называть «студент»). Это означает, что студент самостоятельно, вообще говоря, выбирает некий необходимый, по его мнению, курс, и даже траекторию обучения в целом. Но следует заметить, что курсы и учебные материалы разных вузов, относящиеся к разным направлениям подготовки и будущим специальностям, весьма существенно отличаются и по необходимому уровню предварительной подготовки, и по стилистике изложения, и, главное, по целям освоения курсов.

Во-вторых, в ходе «живых» лекций, семинарских и практических занятий работает еще и такой трудноимитируемый в удаленном режиме 
фактор, как «раппорт» аудитории, когда преподаватель улавливает меру понимания студентами излагаемого материала или конкретные трудности, испытываемые при решении задач, и предпринимает соответствующие меры и усилия, чтобы обеспечить должное понимание и усвоение студентами материала.

В-третьих, еще одной особенностью, возможно, лишь нынешнего этапа развития онлайн-образования - является то, что совокупность публикуемых как бесплатных, так и платных курсов наук явственно разделяется на два почти не пересекающихся класса: курсы «для чайников» и курсы для студентов с очень высокой подготовкой. Середины пока практически нет.

В качестве примера материалов высокого уровня приведем аннотацию содержания курса «Случайные процессы», опубликованного Московским физико-техническим институтом: «Курс посвящен достаточно сложному разделу математики, поэтому от слушателей потребуется хорошее знание базового университетского курса теории вероятностей, а также владение такими основными математическими курсами, как математический анализ и линейная алгебра» (Случайные процессы, Электр. ресурс). По мнению авторов статьи, к перечню необходимых предварительных сведений следовало бы добавить знакомство с началами функционального анализа.

Все это приводит к выводу, что для полноценного освоения материалов онлайн-курсов студент должен заранее обладать фундаментальной подготовкой, и полностью такие курсы не могут заменить даже столь несовершенную форму обучения, как заочная.

Следствием выявленных особенностей оказывается «производство», в подавляющем большинстве, более или менее подготовленных исполнителей стандартных, так сказать, «околонаучных» операций. Кроме того, в условиях онлайн-образования, диктуемого информационным обществом, практически исчезает основа для подготовки кадров научных школ. Такие кадры могут быть подготовлены лишь в условиях традиционного, в основном, обучения, в условиях непосредственного общения участников школы, причем в очень ограниченном количестве - в соответствии с потребностями организаций, курирующих ведущие университеты.

Таким образом, подтверждается положение о том, что в условиях информационного общества все более резким будет становиться различие между относительно очень небольшим количеством и уровнем подготовки выпускников, способных продвигать научные исследования и технологии, и подавляющим большинством (массовый бакалавриат?) выпускников вузов, способных, в основном, применять лишь известные методы (обработки информации) в известных условиях. Следовательно, можно 
ожидать эскалации «расслоения» членов будущего информационного общества по потенциальным уровням участия в его дальнейшем развитии.

\section{СПИСОК ЛИТЕРАТУРЫ}

Акаев, А. А., Садовничий, В. А. (2012) Математическое моделирование глобальной, региональной и национальной динамики с учётом воздействия циклических колебаний // Моделирование и прогнозирование глобального, регионального и национального. М. : Книжный дом «Либроком». С. 23-24.

Башина, О. Э., Минашкин, В. Г. (2014) Статистическое образование: вызовы современности (Шестой технологический уклад - вызовы и перспективы в сфере образования) // Вопросы статистики. № 10. С. 43-47.

Кондратьев, Н. Д., Опарин, Д. И. (1928) Большие циклы конъюнктуры: Доклады и их обсуждение в Институте экономики. М. 287 с.

Левашов, В. К. (2013) Российское государство и общество в период либеральных реформ. М. : ЦСПиМ. 456 с.

Случайные процессы [Электронный ресурс] // Открытое образование. URL: https://openedu.ru/course/mipt/STOCH/ (дата обращения: 12.12.2016).

Яншина, Ф. Т. (1996) Эволюция взглядов В.И.Вернадского на биосферу и развитие учения о ноосфере. М. : Наука. 222 с.

Дата поступления: 13.12.2016 2.

Башина Ольга Эмильевна - доктор экономических наук, профессор, заведующая кафедрой статистики, маркетинга и бухгалтерского учета Московского гуманитарного университета. Адрес: 111395, Россия, г. Москва, ул. Юности, д. 5. Тел.: +7 (499) 374-58-60. Эл. адрес: obashina@mosgu.ru

Николенко Владимир Николаевич - кандидат технических наук, доцент кафедры прикладной информатики Московского гуманитарного университета. Адрес: 111395, Россия, г. Москва, ул. Юности, д. 5. Тел.: +7 (499) 374-70-18. Эл. адрес: nvnram@rambler.ru

Bashina Ol'ga Emil'yevna, Doctor of Economics, Professor and Chair, Department of Statistics, Marketing and Accounting, Moscow University for the Humanities, Honored Worker of Education of the Russian Federation. Postal address: 5 Yunosti St., 111395 Moscow, Russian Federation. Tel.: +7 (499) 37458-60.E-mail: obashina@mosgu.ru

Nikolenko Vladimir Nikolaevich, Candidate of Engineering, Associate 
Professor, Department of Applied Informatics, Moscow University for the Humanities. Postal address: 5 Yunosti St., 111395 Moscow, Russian Federation. Tel.: +7 (499) 374-70-18. E-mail:nvnram@rambler.ru

\section{Для цитирования:}

Башина О. Э., Николенко В. Н. Современное образование и дальнейшее развитие информационного общества [Электронный ресурс] // Научные труды Московского гуманитарного университета. 2016, № 6. URL: http://journals.mosgu.ru/trudy/article/ view/378 (дата обращения: дд.мм.гг.). 